\title{
Israeli-Hezbollah War and Global Financial Crisis in the Middle East and North African Equity Markets
}

Elie I Bouri

Holy Spirit University of Kaslik, Jounieh, Lebanon

\begin{abstract}
This paper, which relies on a dynamic conditional correlation model covering eight years of daily data for twelve equity markets in the Middle East and North Africa, examines the dynamic behaviour of equity returns and the response to international and regional stress periods. We assess whether the Israeli-Hezbollah war and the global financial crisis have accentuated equity linkages and find strong evidence that, although war and financial crisis shocks caused harmful consequences in most MENA markets, there were significant benefits of regional diversification during stress periods in some MENA markets. Low equity correlations across several markets are driven by both the war and the global financial crisis, implying that there still appear to be benefits from regional diversification, especially in the times of stress when it is most needed. Our empirical results are useful for asset managers seeking to construct portfolios that can better resist adverse market conditions.
\end{abstract}

JEL Classifications: F30, G01

Key words: Stress Periods, Dynamic Conditional Correlation, MENA Equity Markets

\footnotetext{
* Corresponding Author: Elie I Bouri; Holy Spirit University of Kaslik, P. O. Box 446 Jounieh, Lebanon, Tel: +9619600800, Fax: +96196008001,E-mail: eliebouri@usek.edu.lb.
} 


\section{Introduction}

The correlation structure between assets play a crucial role regarding hedging and diversification possibilities. Furthermore, it is important to understand the behaviour of the volatility and the correlations of asset returns for pricing, asset allocation, and risk management (Manganelli, 2004). In particular, given that volatility and correlation evolve over time, it has become crucial to incorporate these features into the estimation of the covariance matrix of asset returns in order to maximize portfolio allocation decisions (Harris and Nguyen, 2013). This enables portfolios to become more able to resist periods of market stress, which are times when linkages between asset returns vary dramatically (Pantaleo et al., 2010).

According to Forbes and Rigobon (2002), recent trends of globalization as well as the occurrence of economic and financial crises around the world, including the US stock market crash in 1987, the East Asian crisis in 1997, and the global financial crisis in 2008, were the main catalysts for stronger linkages between national equity markets. Meanwhile, economic ties, cross-border trade, and capital flows are among the main factors that can interlink equity prices (Forbes and Chinn, 2004).

Many researchers have noted an increase in equity market linkages during stress periods, and thus a reduction in diversification benefits (Longin and Solnik, 1995; Ang and Bekaert, 2002; Ang and Chen, 2002); however, the phenomenon of increasing correlation among equity markets remains ambiguous and debatable in the understudied emerging markets of the Middle East and North Africa (MENA) region. In this regard, we seek to focus on the impact of two events, the Israeli-Hezbollah war of 2006 and the global financial crisis of 2008, on conditional variance and correlation across MENA equity markets.

We intend to contribute to the literature in three ways. First, we estimate timevarying conditional variances and correlations across MENA equity markets, including Israel, and show that these variances and correlations change significantly within relatively short time periods. Second, we study asset returns using the Dynamic Conditional Correlation Generalized Autoregressive Conditional Heteroskedasticity (DCC GARCH) approach of Engle (2002), which has the ability to provide timevarying and dynamic conditional correlations between asset returns. Given that financial asset returns are volatile and highly correlated, a multivariate GARCH model emerges as an appropriate framework to study asset returns simultaneously (Nagayasu, 2013). 
While several studies have used the DCC GARCH approach in the case of stocks (e.g. Nagayasu, 2013), our paper extends the analysis by focusing on the understudied markets of the MENA region. Third, we assess the impact of two stress periods on equity return linkages and thus on regional portfolio diversification in order to enhance the reward-to-volatility ratio. Such investigation remains unexplored.

Based on a wide variety of methodologies, prior studies have focused on the issue of efficiency as well as the international integration of the MENA financial markets (Domowitz et al., 1998; Assaf, 2003; Neaime, 2012; Lagoarde-Segot and Lucey, 2008). Others have examined returns and univariate analysis of return volatility in selective stock markets in the MENA region (Al-Rjoub and Azzam, 2012; Alsybaie and Najad, 2009; Brooks, 2007; Khedhiri and Muhammad, 2008), while a few studies have explored the interdependence of volatility of returns between MENA stock markets and developed markets or the oil market (Hammoudeh and Li, 2008; Maghyereh and ALKandari, 2007; Rao, 2008; Khallouli and Sandretto, 2012). Meanwhile, Hammoudeh et al. (2009) have examined the volatility spillovers between three equity sectors (service, banking, and industrial) in Kuwait, Qatar, Saudi Arabia, and the UAE. Recently, Khallouli and Sandretto (2012) have tested for the mean and volatility contagion effect of the US subprime crisis on the MENA stock markets using a Markov switching exponential GARCH framework. We seek to address the impact of two stress periods on dynamic conditional volatility and correlation using a larger sample and different methodology. We also complement the study of Khallouli and Sandretto (2012) by examining portfolio implications.

Over the last three decades, MENA equity markets have experienced rapid growth and expansion; market capitalization grew from nearly US\$200 billion in 2000 to more than US\$1 trillion in 2012. Although MENA constitutes approximately $2 \%$ of the global equity market, the deregulation of global equity markets has promoted a significant inflow of funds into MENA equity markets.

Furthermore, equity markets in the MENA region differ from their counterparts in developed countries in several ways. First, they are typically much smaller and less liquid than world financial markets (Domowitz et al., 1998). Second, they exhibit weakform efficiency and capital market fragmentation because of poor quality information, high trading costs, and low levels of competition (Lagoarde-Segot and Lucey, 2008; Assaf, 2009). Third, several MENA countries have relatively common economic, institutional, regulatory, political, and cultural links that often function differently from those of their developed counterparts. Fourth, the industrial organization found in 
MENA markets is distinct from that in developed economies (Assaf, 2009).

This study involves a heterogeneous sample of equity markets of various sizes, liquidity conditions, and stages of economic development. Israel is a developed economy, while all the other MENA countries are considered as emerging economies.

In addition to their importance for equity allocation and risk management, the empirical results in this paper may be a crucial tool for policymakers that seek stability in financial markets in this turbulent region of the world through timely responses to cross-border shocks.

We provide evidence that there is a sudden increase in conditional volatilities during war or financial crises and show that dynamic conditional correlation of equity market return across the examined markets evolves over time, particularly in times of stress; however, unlike previous findings (Longin and Solnik, 2001; Ang and Chen, 2002; Khallouli and Sandretto, 2012), we find that the correlation between equity market return across several MENA countries decreased during both worldwide and regional bearish market periods, implying diversification benefits during periods of high volatility. While many researchers support the view that the globalization of capital markets reduces diversification on average, regional and international investors may still have an advantage from diversifying into some of the MENA stock markets.

The remainder of the paper is organized as follows: Section II presents the background, evolvements, and final conclusion of the Israeli-Hezbollah war; Section III discusses the methodology including model development; Section IV presents the empirical results including the sample data; and finally, Section V shows the conclusions.

\section{Israeli-Hezbollah War}

On the morning of 12 July 2006, a 34-day military conflict started between the Israeli military and Hezbollah forces. The conflict began when militants from the group Hezbollah attacked a group of Israeli soldiers on the Lebanese-Israeli border, killing eight soldiers and abducting two others. Over the course of the conflict, Israel launched multiple military operations against Hezbollah in Lebanon. The Israeli military's plans called for a sustained bombardment of Lebanon's infrastructure in addition to its plans to destroy Hezbollah military assets. On the other hand, Hezbollah launched rockets 
into northern Israel and engaged the Israeli army in guerrilla warfare from hardened positions. The conflict killed more than 1,300 Lebanese people and 165 Israelis. It severely damaged Lebanese civil infrastructure and displaced more than one million Lebanese and about 500,000 Israelis; however, in the wake of the attack on Qana, in which 28 Lebanese civilians were killed, Israel agreed to a ceasefire. The ceasefire provided the first evidence that Hezbollah had successfully withstood Israeli air attacks and was planning a sustained and prolonged defense of southern Lebanon. Later, the United Nations Security Council unanimously approved UN Resolution 1701 in an effort to end the hostilities. The resolution, which was approved by both the Lebanese and Israeli governments in the following days, called for disarmament of Hezbollah and for withdrawal of Israel from Lebanon (Nakhleh, 2007).

The resolution also called for the deployment of Lebanese soldiers and an enlarged United Nations Interim Force in Lebanon (UNIFIL) in the south Lebanon. UNIFIL was given the ability to use forces to prevent hostile activities in their area of operations. The Lebanese army began deploying in the southern Lebanon on 17 August 2006 and the Israeli blockade on Lebanon was lifted on 8 September 2006. On 1 October 2006, most Israeli troops withdrew from Lebanon. The remains of the two captured soldiers were returned to Israel on 16 July 2008 as the part of a prisoner exchange. To conclude, Israeli armor lost its near invulnerability to Hezbollah arms and the influence of Israeli air superiority was diminished. This brought about various changes in Israel, particularly at the political and military levels. In Lebanon, the impact on sectors of tourism, industry, and services was striking. The local economy lost nearly 7 billion US dollars in the financial terms only. Regionally, the war had implications for several MENA countries, particularly Iran, Syria, Palestine, and Iraq. For Iran and Syria, the war indirectly showed the significance of military forces. Internationally, the war offered an opportunity for Europe to re-engage in the region through UNIFIL (Nakhleh, 2007).

\section{Empirical Methodology}

This section presents the data samples and multivariate model used to examine the time-varying volatility and correlation of returns across MENA stock markets. 


\section{A. Data}

Our data sets consist of the daily closing prices of Morgan Stanley Capital International (MSCI) equity indices for Morocco, Tunisia, Egypt, Israel, Lebanon, Jordan, Kuwait, Bahrain, Qatar, UAE, and Oman. For Saudi Arabia, we used Standard and Poor's Saudi Arabia Broad Market Index (BMI) because MSCI ceased to cover the Saudi equity market. As there is only data for several MENA equity market indices from June 2005, we ensure consistency by only using data covering the period from 1 June 2005 to 30 September 2013. Nevertheless, our data coverage is ideal for this study as it allows us to cover the Israel- Hezbollah war of 2006 and the global financial crisis of 2008. All indices are value weighted and measure the price performance of equity markets without including dividends. Given that most of MENA stock markets do not share the same week-end and public holidays, we select common daily observations using the database of Bloomberg Professional. We calculate the daily returns defined as the difference of the logarithm of price.

Table 1. Descriptive Statistics for Equity Returns of MENA

\begin{tabular}{l|c|c|c|c|c|c|c|c}
\hline & Mean & SD & Skewness & Kurtosis & Jarque-Bera & LB- $Q(5)$ & ARCH-LM (5) & MC/GDP \% \\
\hline Morocco & 0.039 & 1.218 & -0.322 & 7.011 & $507.331^{* * *}$ & $89.735^{* * *}$ & $102.895^{* * *}$ & 77.095 \\
Tunisia & 0.025 & 1.089 & 0.110 & 9.212 & $1209.380^{* * *}$ & $57.879^{* * *}$ & $59.801^{* * *}$ & 25.180 \\
Egypt & -0.009 & 1.809 & -1.195 & 11.089 & $3980.129^{* * *}$ & $39.250^{* * * *}$ & $72.230^{* * *}$ & 39.995 \\
Israel & 0.035 & 1.572 & -0.529 & 8.328 & $1579.721^{* * *}$ & $32.281^{* * * *}$ & $108.995^{* * *}$ & 100.801 \\
Lebanon & 0.023 & 1.681 & -0.032 & 16.281 & $12390.825^{* * * *}$ & $35.752^{* * *}$ & $80.327^{* * *}$ & 31.797 \\
Jordan & -0.059 & 1.329 & -0.702 & 10.210 & $3902.593^{* * * *}$ & $17.980^{* * *}$ & $192.198^{* * *}$ & 102.972 \\
Kuwait & -0.008 & 1.521 & -1.008 & 11.095 & $5581.135^{* * *}$ & $31.239^{* * *}$ & $211.752^{* * * *}$ & 83.872 \\
Bahrain & -0.117 & 1.327 & -2.012 & 30.322 & $52059.327^{* * * *}$ & $21.207^{* * *}$ & $52.072^{* * *}$ & 81.250 \\
Qatar & 0.002 & 1.709 & -0.822 & 12.034 & $5331.893^{* * *}$ & $23.808^{* * *}$ & $171.252^{* * *}$ & 90.595 \\
UAE & -0.081 & 1.780 & -0.612 & 12.755 & $12295.890^{* * *}$ & $35.921^{* * * *}$ & $189.295^{* * *}$ & 52.831 \\
Saudi & -0.035 & 1.893 & -1.098 & 17.303 & $1465.237^{* * *}$ & $18.953^{* * *}$ & $210.583^{* * *}$ & 80.923 \\
Oman & -0.021 & 1.371 & -1.398 & 25.912 & $39895.893^{* * *}$ & $25.588^{* * *}$ & $99.219^{* * *}$ & 35.711 \\
\hline
\end{tabular}

(Note) SD (standard deviation); LB- $Q$ (Ljung and Box $Q$-statistics) measures the serial autocorrelation in the returns up to 5 lags; ARCH-LM (Engle Lagrange multiplier) tests the null hypothesis that there is no presence of an ARCH process in the residuals up to 5 lags; Jarque-Bera tests the null hypothesis of normality of returns; MC/GDP (market capitalization of listed companies as a percent of Gross Domestic Product). For Jarque-Bera, Ljung-Box, and Engle LM tests, ${ }^{* * * *},{ }^{* *}{ }^{*}$ indicate statistical significance at $1 \%, 5 \%$ and $10 \%$ levels respectively. 
Descriptive statistics of MENA equity indices were obtained for the entire period (Table 1). Jordan has the largest ratio of market capitalization of listed companies as a percent of Gross Domestic Product (GDP), while Tunisia has the smallest ratio. We notice that each of the return series has a high value of kurtosis, which implies that the return in each of the MENA stock markets may not be normally distributed. Except for Tunisia, all the return series are negatively skewed. The Jarque Bera test indicates that all series do not have normal distribution. Furthermore, the MENA return series are highly correlated and heteroskedasticity in the residuals of the returns is prevalent. Based on the above characteristics of the data, it is appropriate to use a multivariate GARCH framework, which is capable of eliminating the autocorrelations and heteroskedasticity in the return series (Nagayasu, 2013).

\section{B. Dynamic Conditional Correlation Model}

It is widely accepted that the volatility of asset returns evolves over time. In this view, the assumption that the volatility of return is constant is unrealistic for practical purposes. To deal with this issue, Engle (1982) proposes the Autoregressive Conditional Heteroskedasticity $(\mathrm{ARCH})$ model in which the conditional variance of asset returns depends upon past values of squared returns. Bollerslev (1986) extends Engle's work and proposes the GARCH model in which the conditional variance depends not only upon past values of squared returns but also on past variances. The basic GARCH model of Bollerslev (1986) remains the workhorse for modeling conditional volatility as a time-varying function of current information. In particular, modeling several return series simultaneously allows the conditional variances and co-variances of series to influence each other, leading to more pertinent empirical models than working with an individual univariate GARCH model (Bala and Premaratne, 2004). While numerous extensions of multivariate GARCH models have been proposed, the three most commonly used multivariate GARCH models are the Constant Conditional Correlation (CCC) model of Bollerslev (1990), the Baba-Engle-Kraft-Kroner (BEKK) model defined in Engle and Kroner (1995), and the Dynamic Conditional Correlation (DCC) model of Engle (2002).

The BEKK model may experience convergence problems and unreasonable parameter estimates if used with a large number of variables (Caporin and McAleer, 
2009). In the CCC model, the assumption of constant conditional correlation may seem too restrictive and unrealistic in empirical application. On the other hand, the DCC model overcomes the aforementioned shortcomings and allows for a focus on the dynamic conditional correlation between the time series. More importantly, it models several series at once with meaningful estimated parameters and less computational complications relative to other methods. We thus select the DCC model documented in previous empirical studies (Nagayasu, 2013).

The DCC model examines the dynamic relationship between return series at various points in time, allowing the detection of investor behaviour in response to news and innovations. More importantly, in the DCC model, the estimation of correlation coefficients is based on the standardized residuals and thus accounts directly for heteroskedasticity (Chiang et al. 2007), whereas, with unconditional correlation methods, periods of high volatility can intensify concerns of heteroskedasticity biases (Forbes and Rigobon, 2002). According to Cho and Parhizgari (2008), the dynamic correlation is also adjusted continuously for the time-varying volatility and thus the DCC model provides a superior measure for correlation compared with the volatilityadjusted correlation measure used by Forbes and Rigobon (2002).

The DCC estimates are based on a two-stage approach. First, we estimate timevarying conditional variances by using a GARCH $(1,1)$ model. Second, we estimate a time-varying correlation matrix by using the standardized residuals from the first-stage estimation.

Let $\chi_{t}$ be a vector of asset return, $\mu_{t}$ the expected mean of $\chi_{t}$ obtained from a conditional mean model, and $\varepsilon_{t}$ a vector of innovation, as:

$$
\begin{aligned}
& \chi_{t} \mid I^{t-1} \sim D\left(\mu_{t}, H_{t}\right), \\
& \chi_{t}-\mu_{t}=\varepsilon_{t} \mid I^{t-1} \sim D\left(0, H_{t}\right)
\end{aligned}
$$

The covariance matrix is:

$$
H_{t}=D_{t} R_{t} D_{t}
$$

where $D_{t}=\operatorname{Diag}\left[\sqrt{h}_{i t}, \sqrt{h}_{j t}\right]$

The time varying correlation matrix is decomposed into a diagonal matrix of the 
standard deviations, $D_{t}$, obtained from the estimation of univariate GARCH $(1,1)$ processes,

$$
h_{t}=\alpha_{0}+\alpha_{1} \varepsilon_{t-1}^{2}+\beta_{1} h_{t-1}
$$

and a conditional correlation matrix of the standardized returns, $R_{t}$.

$H_{t}$ is ensured to be positive definite, following the decomposition, by ensuring that $R_{t}$ is positive definite. To this end, we decompose the conditional correlation matrix as:

$$
\begin{aligned}
& \left.R_{t}=\left(\operatorname{Diag}\left(Q_{t}\right)\right)^{-1 / 2} Q_{t} \operatorname{Diag}\left(Q_{t}\right)\right)^{-1 / 2} \\
& R_{t}=Q_{t}{ }^{*-1 / 2} Q_{t} Q_{t}{ }^{*-1 / 2}
\end{aligned}
$$

where $Q_{t}$, the correlation evolution process which has a dynamic structure, in the $\operatorname{DCC}(1,1)$ is:

$$
Q_{t}=(1-\alpha-\beta) \bar{Q}+\alpha\left(\varepsilon_{t-1} \dot{\varepsilon}_{t-i}\right)+\beta Q_{t-1}
$$

where $\bar{Q}_{t}=\operatorname{Diag}\left(Q_{t}\right)$

The dynamic conditional correlation between markets $i$ and $j$ is calculated by:

$$
\rho_{i j, t}=\frac{q_{i j, t}}{\left(\sqrt{q_{i j, t}} \sqrt{q_{j j, t}}\right)}
$$

\section{Empirical Results}

\section{A. Analysis of Conditional Variances}

The parameter estimates of the conditional variance process, GARCH $(1,1)$, under the GED distribution assumption are summarized in Table 2. All of the coefficients of GARCH and ARCH variables are statistically significant at the $1 \%$ level, implying 
that strong GARCH and $\mathrm{ARCH}$ effects are present for the return series. In addition, the estimates satisfy the stationarity conditions for all the variance and covariance processes $(\alpha+\beta<1)$. As the sum of the coefficients $\alpha+\beta$ is close to one for most all of the data series, we imply that volatility is highly persistent in several MENA markets.

For all series the Ljung-Box (1979) statistics indicate that serial correlation in squared residuals is insignificant up to 10 lags, suggesting that the variance processes are well specified.

Table 2. Estimation of the GARCH Process

\begin{tabular}{l|l|l|l|l|c}
\hline & $\omega$ & $\alpha$ & $\beta$ & $\alpha+\beta$ & LB- $Q^{2}(10)$ \\
\hline \hline Morocco & $0.057^{* * *}$ & $0.068^{* * *}$ & $0.893^{* * *}$ & 0.961 & 8.897 \\
Tunisia & $0.061^{* * *}$ & $0.169^{* * *}$ & $0.785^{* * *}$ & 0.954 & 11.984 \\
Egypt & $0.133^{* * *}$ & $0.090^{* * *}$ & $0.872^{* * *}$ & 0.962 & 17.031 \\
Israel & $0.025^{* * *}$ & $0.032^{* * *}$ & $0.953^{* * *}$ & 0.985 & 11.752 \\
Lebanon & $0.125^{* * *}$ & $0.259^{* * *}$ & $0.682^{* * *}$ & 0.941 & 12.957 \\
Jordan & $0.072^{* * *}$ & $0.117^{* * *}$ & $0.873^{* * *}$ & 0.990 & 9.117 \\
Kuwait & $0.140^{* * *}$ & $0.144^{* * *}$ & $0.831^{* * *}$ & 0.975 & 8.872 \\
Bahrain & $0.135^{* * *}$ & $0.165^{* * *}$ & $0.764^{* * *}$ & 0.929 & 12.018 \\
Qatar & $0.129^{* * *}$ & $0.120^{* * *}$ & $0.836^{* * *}$ & 0.956 & 11.089 \\
UAE & $0.215^{* * *}$ & $0.162^{* * *}$ & $0.831^{* * *}$ & 0.993 & 12.250 \\
Saudi & $0.039^{* * *}$ & $0.075^{* * *}$ & $0.919^{* * *}$ & 0.994 & 16.734 \\
Oman & $0.095^{* * *}$ & $0.151^{* * *}$ & $0.801^{* * *}$ & 0.952 & 7.795 \\
\hline
\end{tabular}

(Notes) GARCH $(1,1)$ parameters estimates are based on $h_{t}=\alpha_{0}+\alpha_{1} \varepsilon_{t-1}^{2}+\beta_{1} h_{t-1}$. In this table, the estimated coefficients of the GARCH processes are reported for the full sample period. Based on the Ljung and Box test statistics for the squared residuals, the GARCH $(1,1)$ provided the best fit in the estimation of univariate models. ${ }^{* * *},{ }^{* *},{ }^{*}$ indicate statistical significance at $1 \%, 5 \%$ and $10 \%$ levels, respectively. LB- $Q^{2}$ (Ljung and Box $Q$-statistics for the squared residuals).

To assess the behaviour of conditional variances, we present a comparative analysis of the conditional variances in pre-stress and stress periods. The war period is covered by data from 12 July 2006 through 14 August 2006 and the pre-war period is covered by data from 1 June 2005 through 11 July 2006. The financial crisis period is covered by data from 1 July 2008 through 28 February 2009 and the pre-financial crisis period is covered by data from 1 June 2005 through 30 June 2008. So the pre-financial crisis period includes the pre-war period. 
Table 3. Analysis of Conditional Variance of Equity Returns in MENA

\begin{tabular}{l|c:c:c|c:c:c}
\hline & Pre-war & War & Difference & Pre-crisis & Crisis & Difference \\
\hline Morocco & 1.005 & 1.261 & $25.496 \%$ & 1.145 & 1.553 & $35.633 \%$ \\
Tunisia & 1.229 & 1.395 & $13.469 \%$ & 1.146 & 1.488 & $29.843 \%$ \\
Egypt & $\mathbf{1 . 1 5 8}$ & $\mathbf{1 . 8 1 4}$ & $\mathbf{5 6 . 6 8 2 \%}$ & 1.298 & 2.086 & $60.709 \%$ \\
Israel & $\mathbf{1 . 3 6 5}$ & $\mathbf{1 . 7 7 8}$ & $\mathbf{3 0 . 2 4 2 \%}$ & $\mathbf{1 . 1 0 5}$ & $\mathbf{2 . 0 2 3}$ & $\mathbf{8 3 . 0 7 7 \%}$ \\
Lebanon & $\mathbf{1 . 1 2 1}$ & $\mathbf{1 . 7 8 7}$ & $\mathbf{5 9 . 3 9 8 \%}$ & 1.261 & 1.576 & $24.980 \%$ \\
Jordan & 1.064 & 1.316 & $23.681 \%$ & 1.204 & 1.792 & $48.837 \%$ \\
Kuwait & 1.185 & 1.262 & $6.503 \%$ & 1.225 & 1.356 & $10.694 \%$ \\
Bahrain & 1.129 & 1.185 & $4.930 \%$ & 1.269 & 1.510 & $18.984 \%$ \\
Qatar & 1.144 & 1.507 & $31.714 \%$ & 1.284 & 1.802 & $40.343 \%$ \\
UAE & 1.382 & 1.709 & $23.675 \%$ & $\mathbf{1 . 2 1 3}$ & $\mathbf{2 . 5 7 9}$ & $\mathbf{1 1 2 . 6 1 3 \%}$ \\
Saudi & 1.105 & 1.348 & $21.952 \%$ & $\mathbf{1 . 1 4 2}$ & $\mathbf{2 . 1 2 3}$ & $\mathbf{8 5 . 9 0 2 \%}$ \\
Oman & 1.072 & 1.163 & $8.452 \%$ & 1.212 & 1.385 & $14.290 \%$ \\
\hline
\end{tabular}

(Notes) In this table, the estimated conditional variances of MENA returns are reported for the pre-war war, pre-crisis, and crisis periods. Pre-war period is from June, 12005 to July, 11 2006. War period is from July, 12 2006 to August, 14 2006. Pre-crisis period is from June, 12005 to June, 30 2008. Crisis period is from July, 1 2008 to February, 28 2009. Bold values refer to the three conditional variances that have increased the most the two during stress periods. The value of the conditional variance is based on Equation (3): $h_{t}=\alpha_{0}+\alpha_{1} \varepsilon_{t-1}^{2}+\beta_{1} h_{t-1}$.

From the conditional variances of the pre-stress and stress periods (Table 3), we notice that the conditional variances increased in both the war and financial crisis periods. We also notice that the conditional variances were more influenced by the financial crisis than by the war even if our financial crisis period is compared with precrisis that even includes war period. During the war, the conditional variance increased the most in Lebanon (59\%), followed by Egypt (56\%) and Israel (30\%). This result is not surprising given that the Lebanese economy was the most influenced by the war.

Counter-intuitively, during the financial crisis the conditional variances increased the most in the UAE (112\%), Saudi Arabia (85\%), and Israel (83\%). Although there are major differences between the highly accessible UAE and Israeli markets and the less accessible Saudi market, they all experienced a large increase in volatility in response to the financial crisis. One possible explanation could be a cognitive convergence of domestic investors during the financial crisis as suggested by LagoardeSegot and Lucey (2009). When investors are influenced by others' decisions, cognitive convergence through herding occurs. As such, investors believe that it is optimal to take an action simply because others do take that action as well. 


\section{B. Analysis of Conditional Correlations}

From the average pairwise conditional correlation structure between the MENA markets for the full sample (Table 4), we observe that the lowest correlation is between Morocco and Lebanon (0.017), while the highest correlation is between Qatar and the UAE (0.392).

Table 4. Average Conditional Correlations across the MENA Equity Returns

\begin{tabular}{|c|c|c|c|c|c|c|c|c|c|c|c|}
\hline & Morocco & Tunisia & Egypt & Israel & Lebanon & Jordan & Kuwait & Bahrain & Qatar & UAE & Saudi \\
\hline Tunisia & 0.259 & & & & & & & & & & \\
\hline Egypt & 0.120 & 0.055 & & & & & & & & & \\
\hline Israel & 0.023 & 0.025 & 0.030 & & & & & & & & \\
\hline Lebanon & 0.017 & 0.032 & 0.048 & 0.017 & & & & & & & \\
\hline Jordan & 0.083 & 0.052 & 0.173 & 0.034 & 0.068 & & & & & & \\
\hline Kuwait & 0.061 & 0.098 & 0.104 & 0.021 & 0.059 & 0.125 & & & & & \\
\hline Bahrain & 0.089 & 0.021 & 0.086 & 0.018 & 0.035 & 0.171 & 0.179 & & & & \\
\hline Qatar & 0.068 & 0.018 & 0.255 & 0.025 & 0.081 & 0.179 & 0.180 & 0.162 & & & \\
\hline UAE & 0.089 & 0.072 & 0.310 & 0.093 & 0.057 & 0.205 & 0.231 & 0.198 & 0.392 & & \\
\hline Saudi & 0.095 & 0.063 & 0.252 & 0.059 & 0.014 & 0.129 & 0.154 & 0.268 & 0.389 & 0.259 & \\
\hline Oman & 0.039 & 0.075 & 0.192 & 0.075 & 0.023 & 0.187 & 0.134 & 0.138 & 0.298 & 0.298 & 0.358 \\
\hline
\end{tabular}

(Notes) In this table, the estimated conditional cross-market correlations of MENA returns are reported for the full sample period. The dynamic conditional correlation is based on Equation (5): $\rho_{i j, t}=\frac{q_{i j, t}}{\left(\sqrt{q_{i j, t}} \sqrt{q_{j j, t}}\right)}$.

To assess the behaviour of dynamic conditional correlations, a comparative analysis of the dynamic conditional correlations in pre-stress and stress periods was prepared (Table 5), and these results imply that conditional correlations increased in the war period except for Morocco/Tunisia, Morocco/Qatar, Tunisia/Kuwait, Tunisia/ Oman, Jordan/UAE, and UAE/Saudi Arabia. Based on the percentage decrease in DCC average values, UAE/Saudi Arabia, Tunisia/Kuwait, and Jordan/UAE seem to be the least impacted by the war. This finding implies that the war shock fails to cause completely harmful consequences in these markets. Accordingly, regional investors and portfolio managers could gain from diversification by holding a portfolio of equities from these countries.

Also conditional correlations increased in the financial crisis period except for 
Morocco/Lebanon, Morocco/Qatar, Tunisia/Lebanon, Tunisia/Oman, and Lebanon/ Saudi Arabia. This finding is surprising given that most MENA stock markets are small emerging markets and thus they should be vulnerable to large external shocks. It could be that weak economic and financial ties between these pairs of countries can explain this weak correlation. Based on the percentage decrease in DCC average values, Tunisia/Oman, Tunisia/Lebanon, and Lebanon/Saudi Arabia offer the highest diversification benefits in periods of stress when they are most needed.

Table 5. Dynamic Conditional Correlation across MENA Equity Returns in Stress Periods

\begin{tabular}{|c|c|c|c|c|c|c|}
\hline & \multicolumn{3}{|c|}{ DCC in War periods } & \multicolumn{3}{|c|}{ DCC in Financial crisis periods } \\
\hline & Pre-War & War & Difference & Pre-crisis & Crisis & Difference \\
\hline Morocco / Tunisia & 0.1215 & 0.023 & $-81.07 \%$ & -0.003 & -0.022 & $630.00 \%$ \\
\hline Morocco / Egypt & 0.012 & 0.027 & $120.83 \%$ & 0.028 & 0.040 & $41.38 \%$ \\
\hline Morocco / Israel & 0.038 & 0.052 & $36.84 \%$ & -0.037 & -0.089 & $140.77 \%$ \\
\hline Morocco / Lebanon & 0.007 & 0.009 & $33.14 \%$ & -0.036 & -0.010 & $-72.71 \%$ \\
\hline Morocco / Jordan & 0.012 & 0.022 & $79.17 \%$ & 0.010 & 0.013 & $29.64 \%$ \\
\hline Morocco / Kuwait & 0.011 & 0.028 & $150.00 \%$ & 0.078 & 0.093 & $19.19 \%$ \\
\hline Morocco / Bahrain & 0.021 & 0.052 & $145.24 \%$ & 0.014 & 0.015 & $7.05 \%$ \\
\hline Morocco / Qatar & -0.052 & -0.003 & $-94.23 \%$ & -0.038 & -0.009 & $-76.81 \%$ \\
\hline Morocco / UAE & 0.011 & 0.031 & $177.27 \%$ & 0.009 & 0.013 & $38.10 \%$ \\
\hline Morocco / Saudi & 0.042 & 0.093 & $120.24 \%$ & 0.104 & 0.183 & $75.76 \%$ \\
\hline Morocco / Oman & -0.002 & -0.006 & $175.00 \%$ & 0.001 & 0.002 & $58.33 \%$ \\
\hline Tunisia / Egypt & 0.016 & 0.054 & $234.38 \%$ & 0.054 & 0.057 & $5.52 \%$ \\
\hline Tunisia / Israel & 0.038 & 0.039 & $2.63 \%$ & 0.041 & 0.053 & $29.01 \%$ \\
\hline Tunisia / Lebanon & 0.025 & 0.062 & $146.00 \%$ & 0.014 & -0.008 & $-156.15 \%$ \\
\hline Tunisia / Jordan & 0.005 & 0.018 & $250.00 \%$ & -0.033 & -0.021 & $-36.80 \%$ \\
\hline Tunisia / Kuwait & -0.007 & 0.005 & $-164.29 \%$ & -0.012 & -0.024 & $103.90 \%$ \\
\hline Tunisia / Bahrain & 0.019 & 0.050 & $160.53 \%$ & 0.019 & 0.019 & $5.18 \%$ \\
\hline Tunisia / Qatar & -0.015 & -0.026 & $70.00 \%$ & 0.010 & 0.081 & $756.89 \%$ \\
\hline Tunisia / UAE & 0.006 & 0.035 & $475.00 \%$ & 0.012 & 0.078 & $575.04 \%$ \\
\hline Tunisia / Saudi & 0.039 & 0.098 & $150.00 \%$ & 0.183 & 0.208 & $13.69 \%$ \\
\hline Tunisia / Oman & -0.0759 & -0.019 & $-75.63 \%$ & 0.020 & -0.013 & $-161.58 \%$ \\
\hline Egypt / Israel & 0.042 & 0.121 & $186.90 \%$ & -0.032 & -0.080 & $146.00 \%$ \\
\hline Egypt / Lebanon & 0.014 & 0.028 & $96.43 \%$ & -0.028 & -0.036 & $28.23 \%$ \\
\hline Egypt / Jordan & 0.010 & 0.205 & $1945.00 \%$ & 0.101 & 0.130 & $28.80 \%$ \\
\hline Egypt / Kuwait & 0.028 & 0.192 & $583.93 \%$ & 0.042 & 0.059 & $40.75 \%$ \\
\hline Egypt / Bahrain & 0.039 & 0.215 & $450.00 \%$ & 0.038 & 0.073 & $92.72 \%$ \\
\hline Egypt / Qatar & 0.032 & 0.125 & $289.06 \%$ & 0.120 & 0.141 & $17.53 \%$ \\
\hline Egypt / UAE & 0.023 & 0.189 & $719.57 \%$ & -0.014 & -0.026 & $84.57 \%$ \\
\hline Egypt / Saudi & 0.028 & 0.165 & $487.50 \%$ & 0.051 & 0.098 & $92.45 \%$ \\
\hline Egypt / Oman & 0.025 & 0.108 & $330.00 \%$ & -0.011 & -0.023 & $112.79 \%$ \\
\hline Israel / Lebanon & 0.03 & 0.039 & $30.00 \%$ & 0.078 & 0.079 & $1.28 \%$ \\
\hline
\end{tabular}




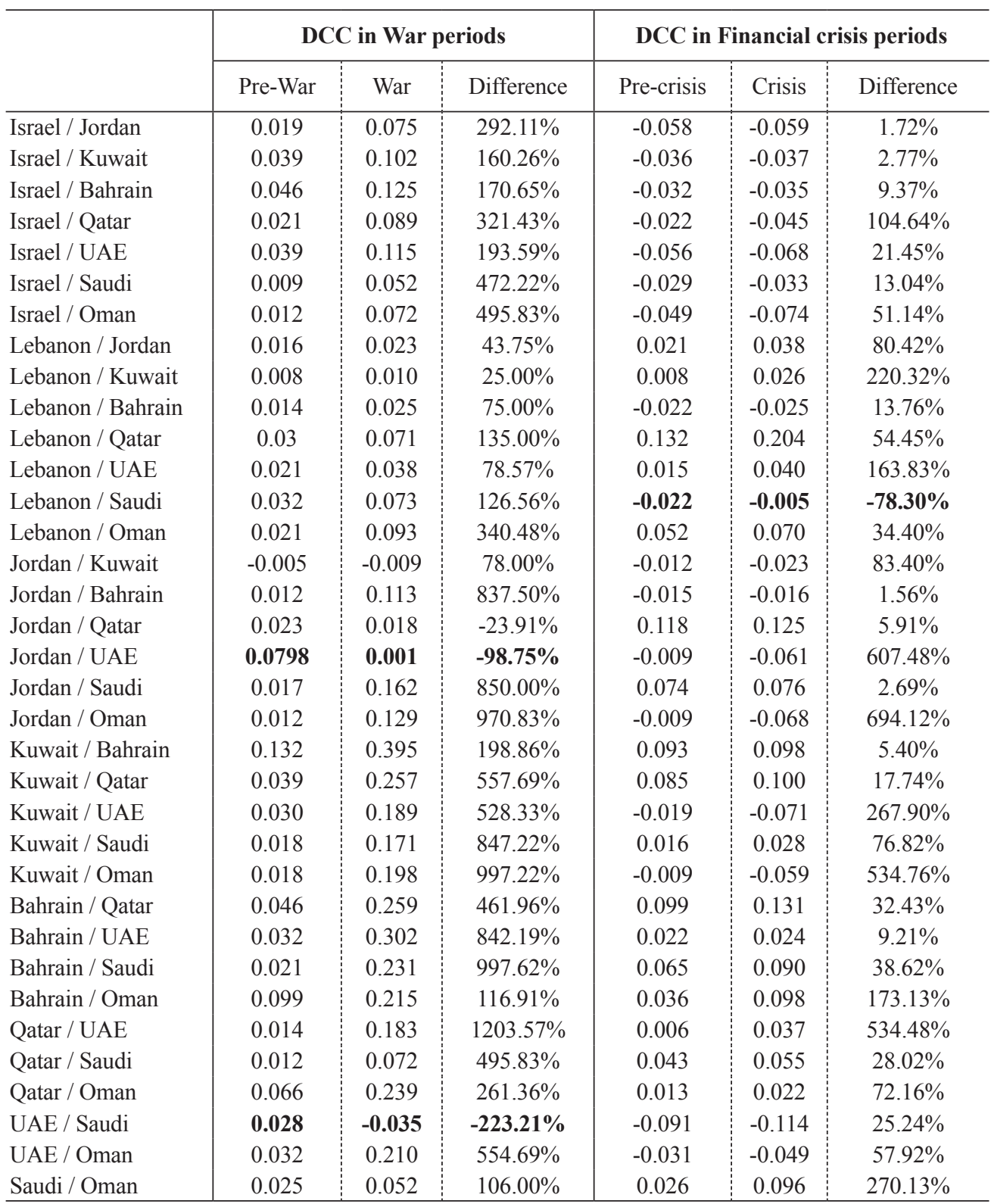

(Notes) In this table, the estimated conditional cross-correlation of MENA returns are reported for the prewar war, pre-crisis, and crisis periods. Pre-war period is from June, 12005 to July, 11 2006. War period is from July, 122006 to August, 14 2006. Pre-crisis period is from June, 12005 to June, 30 2008. Crisis period is from July, 12008 to February, 28 2009. The dynamic conditional correlation is based on Equation (5):

$\rho_{i j, t}=\frac{q_{i j, t}}{\left(\sqrt{q_{i j, t}} \sqrt{q_{j j, t}}\right)}$. 


\section{Concluding Remarks}

The construction of an optimal portfolio entails time-varying volatility and correlation matrices of all the assets in the portfolio, beyond the unrealistic and too restrictive assumption of constant volatility and correlation. Accordingly, this paper applies a DCC GARCH framework and focuses on the effect of global and regional stress periods on the dynamic behaviour of time-varying conditional volatility and correlation across twelve equity markets in the MENA region.

Our first finding is that conditional variances increased during both the war and the financial crisis periods. The magnitude of the volatility spike was larger during the financial crisis. More importantly, our second finding indicates that the conditional correlation across some of the MENA countries is not high in time of crisis. Especially in the pairs of Morocco/Qatar, and Tunisia/Oman, both the war and the financial crisis cause a decrease in the conditional correlation, suggesting the same appreciated benefits of diversification during stress periods. This result is not consistent with earlier studies (Ang and Chen, 2002 and Khallouli and Sandretto, 2012) who find that cross equity market correlations tend to increase during stress periods. According to Bekaert and Harvey (1997), capital flow plays a significant role in emerging market equity returns and volatilities. Weak economic and financial ties between several MENA countries may reduce correlations and in turbulent periods (Valadkhani and Chancharat, 2008), implying stronger possibilities of diversification.

Based on the rationale that correlation is a measure of equity market integration, our empirical finding also implies different levels of integration between the MENA countries, providing a space for regional diversification opportunities. In fact, low response from specific MENA countries to the global financial crisis shows that some countries are still in their infancy with respect to world market integration.

Further investigation is suggested regarding the determinants of equity market correlations such as economic ties, cross-border trade and capital flows, similarities in institutions, regulations, politics, and culture. 


\section{References}

Abraham, A., Seyyed, F.J. and Al-Elg, A. (2001), "'Analysis of diversification benefits of investing in the emerging gulf equity markets”, Managerial Finance, Vol. 27, pp. 47-57.

Ang, A. and Bekaert, G. (2002), "International asset allocation with regime shifts", Review of Financial Studies, Vol. 15, pp. 1137-1187.

Ang, A. and J. Chen (2002) "Asymmetric correlations of equity portfolio", Journal of Financial Economics", Vol. 63, pp. 443-494.

Al-Rjoub, S. and Azzam, H. (2012), "Financial crises, stock returns and volatility in an emerging stock market: the case of Jordan”, Journal of Economic Studies, Vol. 39, pp.178-211.

Alsybaie, A. and Najad, M. (2009), "Trading volume, time-varying conditional volatility, and asymmetric volatility spillover in the Saudi stock market", Journal of Multinational Financial Management, Vol. 19, pp. $139-159$.

Assaf, A. (2003), "Transmission of stock price movements: the case of GCC stock markets", Review of Middle East Economics and Finance, Vol. 1, pp. 171-189.

Assaf, A. (2009), "Extreme observations and risk assessment in the equity markets of MENA region: Tail measures and Value-at-Risk", International Review of Financial Analysis, Vol. 18, pp. 109-116.

Bala, L. and Premaratne, G. (2004), "Volatility spillover and co-movement: some new evidence from Singapore", Midwest Econometrics Group (MEG) Fall Meetings North Western University Evanston.

Bauwens, L., Laurent, S., and Rombouts, J.V. K. (2006), "Multivariate GARCH models: a survey", Journal of Applied Econometrics, Vol. 21, pp. 79-109.

Beine, M. Laurent, S. and Lecourt, C. (2000), "Accounting for conditional leptokurtosis and closing days effects in FIGARCH models of daily exchange rates", Applied Financial Economics, Vol. 12, pp. 589-600.

Bekaert, G. and Harvey, C.R. (1997), "Emerging equity market volatility", Journal of Financial Economics, Vol. 43, pp. 403-444.

Bekaert, G. and Wu, G. (2000), "Asymmetric volatility and risk in equity markets" Review of Financial Studies 13 , pp.1-42.

Bollerslev, T. (1986), "Generalized autoregressive conditional heteroscedasticity", Journal of Econometrics, Vol.31, pp. 307-327.

Bollerslev, T. (1990), "Modelling the coherence in short-run nominal exchange rates: a multivariate generalized ARCH approach", Review of Economics and Statistics, Vol. 72, pp. 498-505.

Bollerslev, T., Engle, R.F. and Wooldridge, J.M. (1988), "A capital asset pricing model with time-varying covariance", Journal of Political Economy, Vol. 96, pp.116-131.

Boudt, K. and C. Croux (2010), "Robust M-Estimation of Multivariate GARCH Models", Journal Computational Statistics and Data Analysis, Vol. 54, pp. 2459-2469

Brooks, R. (2007), "Power ARCH modelling of the volatility of emerging equity markets", Emerging Markets Review, Vol. 8, pp.124-133.

Caporin, M. and McAleer, M. (2009), "Do We Really Need Both BEKK and DCC? A Tale of Two Covariance 
Models", Available at SSRN: http://ssrn.com/abstract=1338190.

Chiang, T.C., Jeon, B.N. and Li, h. (2007), "Dynamic correlation analysis of financial contagion: evidence from Asian markets", Journal of International Money and Finance, Vol. 26, pp. 1026-1228.

Cho, J.H. and Parhizgari, A.M. (2008). "East Asian financial contagion under DCC-GARCH", International Journal of Banking and Finance, Vol. 6, pp. 17-30.

Claessens, S., Dasgupta, S. and Glen, J. (1995), "Return behavior in emerging stock markets", World Bank Economic Review, Vol. 9, pp.131-152.

Domowitz, I. Glen, J. and Madhavan, A. (1998), "International cross-listing and order flow migration: Evidence from an emerging market", Journal of Finance, Vol. 53, pp.2001-2027.

El-Erian, M.A., and Kumar, M.S. (1995), "Emerging equity markets in Middle Eastern countries", IMF Staff Paper number 42

Engle, R. (1982), “Autoregressive conditional heteroscedasticity with estimates of the variance of United Kingdom inflation”, Econometrica, Vol.50, pp. 987-1007.

Engle, R. (2002), Dynamic conditional correlation: a simple class of multivariate generalized autoregressive conditional heteroskedasticity models, Journal of Business and Economic Statistics, Vol. 20, pp. 339-350.

Engle, R.F. and Kroner, K. F. (1995), "Multivariate simultaneous generalized ARCH", Econometric Theory, Vol. 11, pp. 122-150.

Forbes, K. J. and M. D. Chinn (2004), "A Decomposition of Global Linkages in Financial Markets over Time", The Review of Economics and Statistics, Vol. 86, pp. 705-722.

Forbes, K.J. and Rigobon, R. (2002), "No contagion, only interdependence: measuring stock market comovements", Journal of Finance, Vol. 57, pp. 2223-2261.

Hammoudeh, S. and Li, H. (2008), "Sudden changes in volatility in emerging markets: The case of Gulf Arab stock markets", International Review of Financial Analysis, Vol. 17, pp.47-63.

Hammoudeh, S., Yuan, Y. and McAleer, M. (2009), "Shock and volatility spillovers among equity sectors of the Gulf Arab stock markets" The Quarterly Review of Economics and Finance 49, pp.829-842.

Harvey, C. (1995), "Predictable risk and returns in emerging markets", Review of Financial Studies, Vol. 8, pp. 773-816.

Janakiramanan, S. and Lamba, A.S. (1998), "An empirical examination of linkages between Pacific-Basin stock markets”, Journal of International Financial Markets, Institutions and Money, Vol. 8, pp.155 -173.

Jarque, C. and Bera, A. (1980), "Efficient tests for normality, homoscedasticity and serial independence of regression residuals", Economics Letters, Vol. 6, pp.255-259.

Khallouli, W. and Sandretto, R. (2012), "Testing for "Contagion" of the Subprime Crisis on the Middle East and North African Stock Markets: A Markov Switching EGARCH Approach", Journal of economic Integration, Vol. 27 No.1, pp. 134-166.

Khedhiri, S. and Muhammad, N. (2008), "Empirical Analysis of the UAE Stock Market Volatility", International Research Journal of Finance and Economics, Vol. 15, pp.249-260.

Kring S., Rachev S. T., Hochstotter, M. and Fabozzi, F. J. (2007), “Composed and Factor Composed Multivariate GARCH Models", University of Karlsruhe, Technical Report. 
Kroner, K.F. and Ng, V.K. (1998), "Modeling asymmetric comovements of asset returns", Review of Financial Studies, Vol. 11, pp.817-844.

Lagoarde-Segot, T. and Lucey, B. (2008), "Efficiency in emerging markets-Evidence from the MENA region", Journal of International Financial Markets, Institutions and Money, Vol. 18, pp. 94-105.

Lagoarde-Segot, T. and Lucey, B. (2009), "Shift-contagion vulnerability in the MENA stock markets", The World Economy, Vol. 32, pp. 1478-1497.

Lee, S.J. (2009), "Volatility spillover effects among six Asian countries" Applied Economics Letters 16, pp. 501- 508 .

Ling, S. and McAleer, M. (2003), "Asymptotic theory for a vector ARMA-GARCH model”, Econometric Theory, Vol. 19, pp. 278-308.

Ljung, G. and Box, G. (1979), "On a measure of lack of fit in time series models", Biometrika, Vol. 66, pp. 265-270.

Longin, F. and Solink, B. (1995), “Is correlation in international equity returns constant: 1960-1990?", Journal of International Money and Finance, Vol. 14, pp. 3-26.

Longin, F. and B. Solnik (2001) "Extreme correlation of international equity markets", Journal of Finance, Vol. 56, pp. 649-676.

Maghyereh, A. and AL-Kandari, A. (2007), "Oil prices and stock markets in GCC countries: new evidence from nonlinear co-integration analysis", Managerial Finance, Vol. 33, pp. 449-460.

Nagayasu, J. (2013), “Asia-Pacific Stock Returns around the Lehman Shock and Beyond: time-varying conditional correlations", Journal of Economic Integration, Vol. 28 No.3, pp. 412-440.

Nakhleh, H. (2007), "The 2006 Israeli war on Lebanon: Analysis and strategic implications", Strategic Research Project, U.S. Army War College, USA.

Manganelli, S. (2004), “Asset Allocation by Variance Sensitivity Analysis", Journal of Financial Econometrics, Vol. 2, pp. 370-389

Neaime S. (2012), "The global financial crisis, financial linkages and correlations in returns and volatilities in emerging MENA stock markets”, Emerging Markets Review, Vol. 13, pp. 268-282.

$\mathrm{Ng}$, A. (2000), "Volatility spillover effects from Japan and the US to the Pacific-Basin", Journal of International Money and Finance, Vol. 19, pp. 207-233.

Pantaleo, E., M. Tumminello, F. Lillo, and R.S. Mantegna (2010), "When do improved covariance matrix estimators enhance portfolio optimization? An empirical comparative study of nine estimators", Quantitative Finance, Vol. 11, pp. 1067-1080.

Patton, A. (2000), "Modelling time-varying exchange rate dependence using the conditional copula", University of California, San Diego, Discussion Paper 01-09.

Poon, S.-H., Rockinger, M. and Tawn, J. (2004), "Extreme value dependence in financial markets: diagnostics, models, and financial implications", The Review of Financial Studies, Vol. 17, pp. 581-610.

Rao, A. (2008), "Analysis of volatility persistence in Middle East emerging equity markets", Studies in Economics and Finance, Vol. 25, pp. 93-111.

Rossi, J.L., Ehlers, R.S. and Andrade, M.G. (2012), "Copula-GARCH Model Selection: A Bayesian Approach”, University of São Paulo, Technical Report 88. 
Serban, M., Brockwell, A., Lehoczky, J. and Srivastava, S. (2007), "Modelling the dynamic dependence structure in multivariate financial time series", Journal of Time Series Analysis, Vol. 28, pp. pp. 763-782.

Valadkhani, A. and Chancharat, S. (2008), "Dynamic linkages between Thai and international stock markets", Journal of Economic Studies, Vol. 35, pp. 425-441.

Yu, Junk-Suk and Hassan, M. K. (2008), "Global and regional integration of the Middle East and North African (MENA) stock markets", Quarterly Review of Economic and Finance, Vol. 48, pp. 482-504. 